\title{
RISK MANAGEMENT DECISION MAKING
}

\author{
Rabihah Md.Sum \\ Department of Applied Finance and Actuarial Studies \\ Faculty of Business and Economics \\ Macquarie University \\ Sydney 2109 Australia \\ E-mail: $\underline{\text { rabihah.md-sum@mq.edu.au }}$
}

\begin{abstract}
This research discusses the possibility and usefulness of using Analytic Hierarchy Process (AHP) as a tool for decision making in risk management. The study is motivated by the wide application of AHP in finance and banking. AHP as a decision making tool is widely applied in supply chain risk management and project risk management. The application of AHP in the risk management of an enterprise has not yet been explored. Risk management is an established and accepted process as evidenced by much research in this area and published regulations and standards. Despite this decision making in risk management tends to be informal depending on intuition and marked by an absence of formal analyses. AHP is able to assist decision maker in making complex decision. To see whether AHP is the tool for risk management a distinction between risk management and risk management decision making is made. Potential application in risk management is discussed. An example of risk management decision making problem is presented to show how risk management decision making problem is structured using AHP.
\end{abstract}

Keywords: risk management, decision making, analytic hierarchy process

\section{Introduction}

This research discusses the possible application of AHP (Saaty, 1980) in risk management. The aim is to answer the question if AHP a useful tool for decision making in risk management. AHP is used in various area such as education, engineering, government, industry, management, manufacturing, personal, political, social and sports (Vaidya \& Kumar, 2006). In finance AHP is applied in capital budgeting, selecting financial instruments, mergers and acquisition, predicting bankruptcy and forecasting foreign exchange rate (Stuer \& Na, 2003; Zopounidis \& Doumpos, 2002). AHP in risk management is mainly applied in project risk management and supply chain risk management (Verbano \& Venturini, 2011).

Risk management is the process of identifying risks and planning actions to manage the risks. The identified risks are assessed and prioritized. Only significant risks are managed. Risk management decision making is a process to select the best alternatives or rank the alternatives for a specific risk management goal. The ultimate goal is to create, protect and enhance shareholder value by managing uncertainties influencing the achievements of the firm's objectives (Barton, Shenkir, \& Walker, 2002). Risk management decision problems involve many conflicting factors and alternatives. Many aspects of the decision making involve a lot of intangibles. Often risk managers have to make a high-stake decisions based on practically unlimited information but limited time to analyse and organize the information. Uncertainty and instability of the business environment also contributes to the complexity of risk management decision making. Similar situation faces the field of finance. Increased complexity with multiple conflicting factors in the problem forces financial decision makers to adopt multi criteria decision making (MCDM) approach (Zopounidis \& Doumpos, 2002). AHP one of MCDM is widely used in financial decision making. The AHP methodology is able to capture the complexity of financial decision making.

Following the successful application of AHP in financial decision making, this research aims to explore the possibility to use AHP in risk management decision making problem. Section 2 presents a review of previous studies on AHP as a decision making tool and research area in risk management. Section 3 discusses the distinction between risk management and risk management decision making. Section 4 
discusses potential applications of AHP in risk management decision problems. Finally section 5 discusses an example of risk management decision making problems and how AHP is used to structure the problem.

\section{AHP and risk management}

This section reviews previous studies on application of MCDM and AHP. The focus is on the application of AHP in risk management. The section starts with a review of current literature in risk management. Followed by a review of current literature in decision making in risk management and finance.

The following literature discuses the research area of risk management. Studies on risk management mainly focus on the effect of risk management on firm value (Hoyt \& Liebenberg, 2011; Gordon, Loeb, \& Tseng, 2009; Beasley, Pagach, \& Warr, 2008), how to implement risk management (Pagach \& Warr, 2011; Nocco \& Stulz, 2006), factors that caused firm to implement risk management (Acharyya, 2009) and measuring risk and capital requirement (Toneguzzo, 2010; Panning, 2006). Iyer, Rogers, and J.Simkins (2010) analyses published studies on enterprise risk management (ERM). The study the focus of ERM research are on the effect of risk management to firm performance, factors determining the implementation of risk management, the extent of risk management implementation and, the theory and practice of risk management. Through method of visualization Ping Zhuang and Qu (2008) maps core research group of enterprise risk management. Eleven research groups are identified: quality management, risk management practices, financial risk management, insurance company, health risks, electricity price, risk factors, risk reduction, process safety management, market conditions and risk assessment. Verbano and Venturini (2011) analyses new path of development and application of risk management. The study identifies nine main paths of development: strategic risk management, financial risk management, enterprise risk management, insurance risk management, project risk management, engineering risk management, supply chain risk management, disaster risk management, clinical risk management. The study lists the tools used to manage risks in each area. Among the tools identified is AHP. However, AHP is only used in project risk management and supply chain risk management.

MCDM tools are used extensively in financial decision making. The complexity of the problem and the importance of the decision forces researchers and practitioners in finance to use analytic decision making tool. Zopounidis and Doumpos (2002) discusses the application of multi criteria decision aid (MCDA) in finance. MCDA is applied to bankruptcy and credit risk, portfolio selection and management, corporate performance evaluation, investment project decision, venture capital, country risk assessment, financial planning and, mergers and acquisition. The MCDA methods use in the studies are AHP, Elimination Et Choix Traduisant la Realite (ELECTRE), Multiattribute Utility Theory (MAUT), Multi-Group Hierarchical Discrimination (MHDIS), Preference Ranking Organization Method of Enrichment Evaluations (PROMETHEE), Utilities Additives (UTA) and Utilities Additives Discriminantes (UTADIS). The wide application of MCDA in financial issues proves MCDA is well suited to handle complex financial decision making. Stuer and $\mathrm{Na}$ (2003) finds 256 publish studies since 1955-2001 on MCDM application for finance. From the 256 papers 18 papers use AHP as the decision making methodology. AHP is used in making decisions on capital budgeting, selecting financial instruments, mergers and acquisition, predicting bankruptcy and forecasting foreign exchange rate. The remaining papers use other MCDA methodologies such as goal programming, multiple objective programming, MAUT and ELECTRE.

Vaidya and Kumar (2006) shows AHP can be used on six types of decisions; selecting one alternative from many, evaluation of alternatives, benefit-cost analysis, resource allocations, planning and development, and priority and ranking. The study finds 150 publish papers on AHP application from 1990 to 2003. The area of application includes education, engineering, government, industry, management, manufacturing, personal, politics, social and sports. Sipahi and Timor (2010) present detail bibliography studies on AHP and Analytic Network Process (ANP) application from 2005 to 2009. A total of 235 papers is published indicating increased in research on AHP and ANP. The application of AHP is dominant in manufacturing, followed by environmental management and agriculture, power and energy industry, transportation industry, construction industry and healthcare. The most common decision making issues solved using AHP are supplier selection, supply chain evaluation, location selection, system selection or evaluation, and strategy evaluation. AHP and ANP also use in education, 
logistics, e-business, information technology, research and development, telecommunication industry, finance and banking, urban management, defence industry and military, government, marketing, tourism and leisure, archaeology, auditing, mining industry, sports and politics. The study also documents AHP and Fuzzy AHP is the most used decision making methodology compared to other MCDM tools. Eshlagy and Homayanfar (2011) find 628 papers on MCDM from 1999 to 2009. The area of MCDM application includes environmental management, water management, business and financial management, transportation and logistics, manufacturing and assembly, energy management, agricultural and forestry management, managerial and strategic planning, project management and evaluation, social service and military service. From 628 papers, 11 papers are on AHP application in business and financial management. The area of application includes investment project assessments, financial alliances, stock selection, foreign direct investment, partnership selection and merger strategy.

The vast and diverse application of AHP is a prove AHP is a credible decision making tool. AHP can handle complex decision making in almost any area. One of the major area of application is in financial decision making. However, AHP as a decision making tool in risk management is used widely only in supply risk management and project management. Similar to financial decision making decision making in risk management are complex and involves many conflicting factors. The lack of studies in risk management motivates this research to explore whether AHP can be used as a decision making tool in risk management.

\section{Risk management decision making}

This section explains the distinction between risk management and risk management decision making. Risk management is the process to identify risks and plan actions to manage the risks. The identified risks are assessed to determine significant risks. Significant risks are risks preventing firms from achieving business objectives or risks disrupting core business process. Firms then plan the best way to minimize the risks. Identifying significant risks enable firms not only to manage risks that matters but to efficiently allocate resources to manage the risks. A firm is exposed to many risks. Managing the risks involves many tasks. If the tasks are not structured firms will be overwhelmed by the number of actions to undertake to manage each risk. Risk management is a tool to structure the tasks. Risk management provides a step by step process to manage risks. The steps start with identifying risks firms are exposed to, assess the risks to determine significant risks and plan responses to the risks. Risk management is an iterative process. The process must be reviewed from time to time. New risks emerge, some risks do not materialize, venture into new market and the development of new risk response methods are some of the reasons firms needs to review risk management. The four steps (identify, assess, plan and review) are the basis to undertake risk management. Risk management standards such as the Committee of Sponsoring Organizations of Treadway Commission (COSO) and the AS/NZS 4360:2004 Risk Management provides comprehensive steps to undertake risk management.

A key part of risk management is making decisions. Borge (2001) states the power of risk management lies in the ability of the risk manager to make good decisions. Risk management decision making is selecting the best alternatives or ranking the alternatives for a specific risk management goal. For example identifying risks face is risk management. Choosing the best method to identify risk with the aim to expedite the risk management process is risk management decision making. Determining significant risks affecting core business is risk management.Ranking the significant risks based on criteria such as is the risk transferable, does the risk have a long term effect on the firm or does the firm has the resources to manage the risk is risk management decision making. Techniques to implement risk management are well developed. Among the techniques to identify risks are brainstorming, Delphi Technique and scenario analysis. Among the techniques to assess risks are risk mapping and risk matrix chart. The techniques enable firms to determine important risks and decide the best actions to manage the risk. However, the decisions are based on only one factor basically risks affecting business objectives or risks affecting core business process. In practical firm have to consider many factors and face with many alternatives in making decision in risk management. Risk management decisions rarely involve only one or two criteria or a yes and no answer. This situation requires a decision making tool able to handle the complexity of risk management problems. The tool must also able to incorporate risk management principles in the overall goal of the decision making. 
Grunig and Kuhn (2005) states a complex problem has at least one of the following criteria; the problem has many dimensions, problem parameters are interdependent creating an unclear problem structure, more than one department in the company is included in the problem, a large number of possible solutions exist and environment where the decision is made is uncertain. If none of the criteria exist the problem is a simple decision problem. Risk management decision problem fits the characteristics of a complex problem. Decision problems in risk management are unstructured with many criteria influencing the problem and solutions to the problem. Risks are interrelated and evolves requiring constant reviewing of the decisions. Decision making in risk management requires a tool able to handle conflicting multiple factors across different range of risk management situations.

Risk management decision making consists of three areas:

Risk identification and assessment. How to identify risks? What is the best method to obtain a comprehensive list of risks? How to determine which risks are important? The central issue is to determine which risks are significant and what are the factors to use to determine the significance of the risks?

Risk responses. How much risk firms are willing to take? What is the best method to address the risks? How to choose the best method? How much resources firms are willing to allocate to manage the risks? The central issue is to address the prioritized list of risks with a concrete risk response planning.

Risk review. The environment where the decision is made changes over time. New information or new alternative emerges forcing firms to consider previous decisions. The purpose of risk review is to monitor the effectiveness of the chosen risk response and to monitor new risks.

\section{Application in risk management}

This section discusses the potential application of AHP as a decision making tool in risk management problems. In general AHP is the use of five types of decisions; making a choice among a given set of alternatives, prioritizing alternatives, resource allocation, comparing a business process with other business processes, and synthesize quantitative and qualitative factors in total quality management (Forman \& Gass, 2001). For risk management problems AHP can be used in making a choice amongst alternative, prioritization of alternatives and resource allocation. Each of the three potential applications is highlighted in this section.

Choosing one alternative from a set of alternatives. Decision making in risk management is not often about choosing one risk management alternative from a number of alternatives. However it is useful to consider this possibility. An example of a decision making situation requiring the decision maker to choose only one alternative is a plan to adopt a risk management framework. For example a firm planning to use ISO31000 Risk Management Standard as a framework for the risk management program. The problem whether or not to adopt a standard risk management framework requires a multi criteria decision making tool because of the conflicting factors influencing the decision. Planning to adopt a risk management framework raises few issues such as does the organization has the resources to implement the framework, can the management commit to the framework and how to ensure top management and all employees understand and support the framework. Instead of debating over which standards are the best firm can structure the problem in a hierarchy. Taking into consideration success factors, cost and benefits firms can objectively decide which risk management standards to adopt.

Prioritizing alternatives. One of major AHP applications in risk management decision making is prioritization. Many problems in risk management require decision maker to prioritize the alternatives. One of the potential major application of AHP is to prioritize risks preventing firms from achieving business objectives. Risk management is the process to identify, assess and manage risks. From the identification and assessment firms develops a risk profile. The risk profile is a list of key risks preventing firms from achieving business objectives. The risk profile is presented in a risk matrix. A risk matrix consists of columns representing probabilities or frequency and rows representing severity or impact. Risk matrix is risk priority based on frequency and severity. Cox Jr et al. (2008) argues the ability of risk matrix to improve decision making in risk management since the risk matrix is commonly used when quantitative data are limited or unavailable. Cox argues the mathematical properties of risk matrix have several limitations (1) Risk matrices can only make an accurate comparison on a small number (less than 10\%) of randomly selected hazards (2) Risk matrix can mistakenly assign higher qualitative ratings to quantitatively smaller risks (3) Effective resource allocation to mitigate risks 
cannot be based on risk matrices (4) Ratings in the risk matrices depends on the subjective judgements of the decision maker. Different decision makers have opposite ratings on the same risk. Using AHP to prioritize risk will complement decision making in risk management relying solely on risk matrix. The basis to prioritize risk in risk matrix is limited to only two criteria probability and severity. AHP has no limit on the number of criteria and no constraint on the criteria must be quantitative. The flexibility enables firms to structure the problem according to criteria view important to the business objectives. Risk ranking obtains from AHP can be used to complement risk priority obtain from the risk matrix.

Resource Allocation. Resource allocation is finding the best combination of alternatives subject to a variety of constraints. Resource allocation in risk management is allocating firm's expenditure to manage risks preventing successful achievement of business objectives. Normally firms allocate resources based on risk matrix. The risk matrix chart is divided into four quadrants. Significant risks are placed in the quadrant based on severity and probability. For each quadrant firm plan a suitable response and allocate expenditure to implement the response. In a situation firm has limited resources to manage every significant risk only risks with the largest impact to business objectives are managed. The risk matrix is a useful reference to determine the suitable actions and allocate expenses to manage the risks. However the decision is based only on the severity and likelihood. AHP can prioritize risk mitigation actions based on other important criteria. For example the probability of the risks to occur can be divided into three categories; near-term, midterm and long-term. The firm then uses the criteria to allocate resources to mitigate the risks. Firm can allocate resources based on benefits such as amount of risk reduce or increase in firm performance. Saaty (1990) suggests to develop a separate hierarchy for benefit and cost. If the benefits are more important than the cost, the decision is based only on the benefits. If the benefits do not justify the costs the decision is based on the least cost alternative. For the benefit hierarchy the significant risks and risk mitigation actions are prioritized based on the risk reduction benefits. If cost is the main problem in allocating resources a separate hierarchy is developed. The aim is to obtain the best combination of risk mitigation actions with the least cost. For example transferring catastrophe risk to a third party requires a large cost but bring many benefits to the firm.

Separating resource allocation decision making into the benefits and costs assist firms to make accurate decisions on the two conflicting issues.

\section{Risk management problem example}

This section analyses and discusses an example of application of AHP in risk management decision making. The problem is for a firm to decide actions to achieve their risk management objectives. First the risk management objectives are translated into measurable attributes. Achieving the attributes indicates the firm has a successful risk management program. Second the firm determines the alternatives. The alternatives are risk management actions to achieve risk management objectives. The risk management objectives of the firm (Hopkin, 2010, p. 64), the risk management objectives measurable attributes and the risk management actions are given in Figure 1. The decomposition of the problem is presented in Figure 2.

Explanation of the risk management actions is as the following:

Identify and assess risks. The process of risk identification includes ranking the risks based on frequency and severity, creating a probability distribution outcome for each material risks and developing benchmarks to determine the materiality of the identified risks. The outcome of the risk identification process is a risk profile indicating the significance rating to each material risk. The process also includes determining the contribution of each risk to the aggregate risk profile taking into consideration the effect of correlations among the risks.

Transfer risks. Where appropriate transfer risks to financially capable third party at a reasonable economic cost. Risks can be transferred to insurance markets, to capital markets, by joint venture investments, by outsourcing arrangement and by indemnifying risk through contractual agreements.

Effective and efficient risk communication and reporting. Firms need to speak the same risk language and understand each other fully. Firms can adopt a common risk language by using a consistent risk terminology and producing a glossary of risk terms where appropriate. 
Figure 1: Risk Management Objectives, Measures and Actions

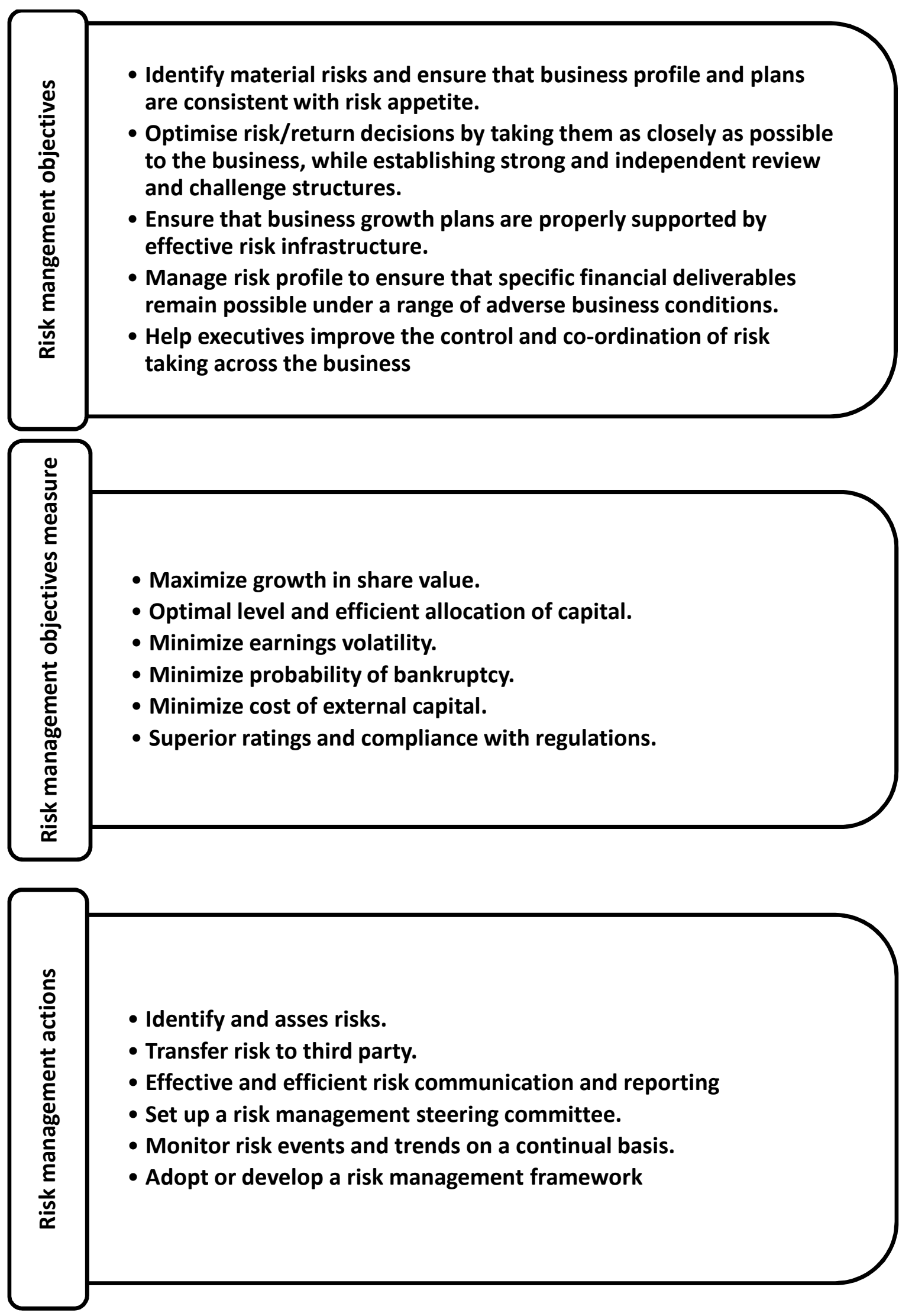


Set up a risk management steering committee. Designate a risk champion (Chief Risk Officer or Head of Risk Management) for the risk process to be institutionalized. Clearly define key roles and responsibilities.

Monitor risk. Monitor risk events and trends on a continual basis. Recent financial crisis has proven companies suffering the greatest losses failed to recognize risks.

Adopt or develop a risk management framework. Implementing risk management is a complex process. To ensure effective and efficient implementation firm could either develop their own risk management framework or adopt one of the many published risk management frameworks.

Figure 2: Risk Management Objectives and Actions Hierarchy

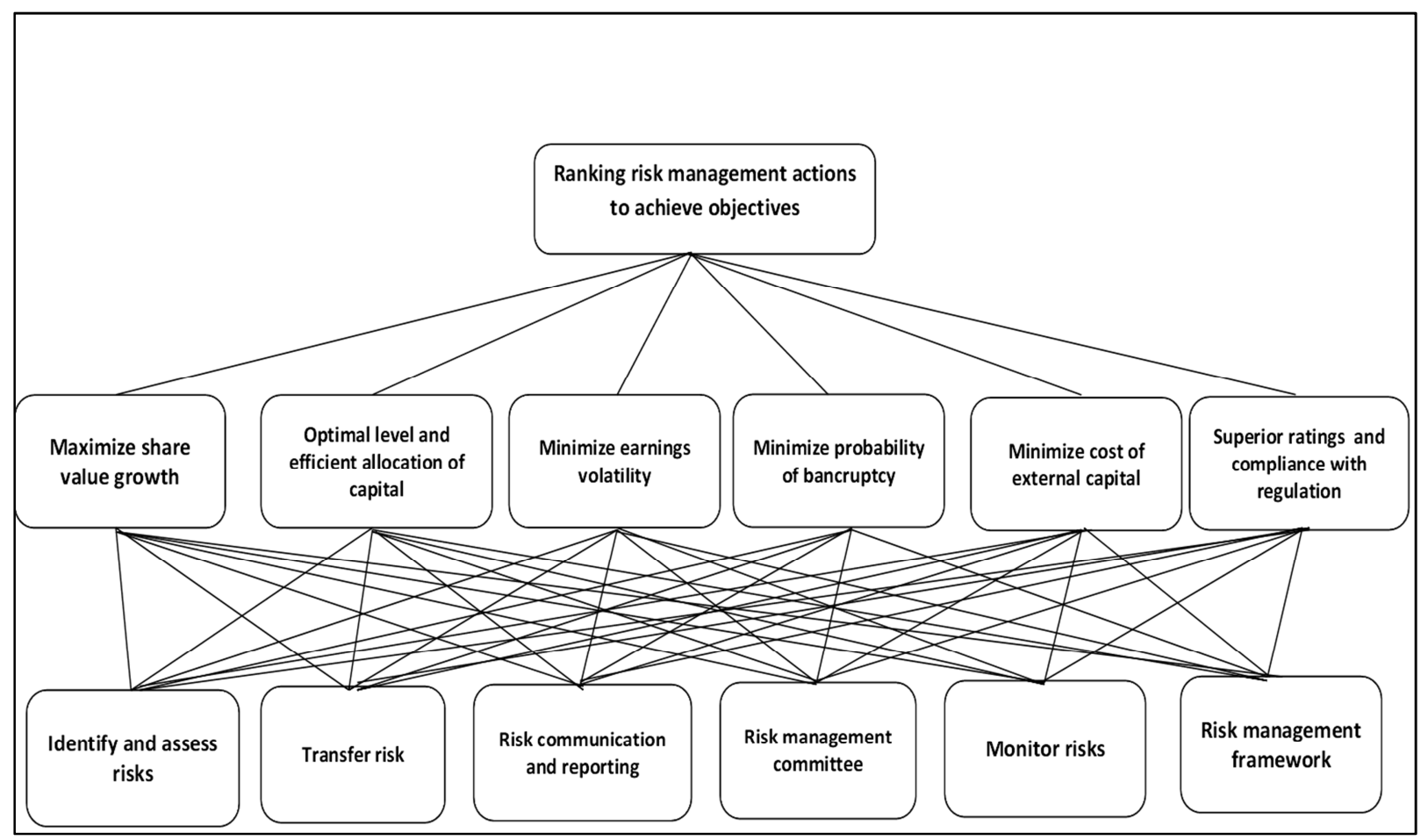

The first level is the overall goal ranking risk management actions to achieve risk management objectives. The second level is the criteria, the risk management objectives. The third level is the alternatives, risk management actions to achieve the objectives. The question asks in the pairwise comparison is of the two risk management actions being compared which is more preferred or effective to achieve the risk management objective. The judgements are entered into a pairwise comparison matrix. AHP uses the eigenvalue method to obtain the priority vector.

The pairwise comparison judgement and the priority vector are obtained as the following. Write $P=\left\{P_{l}\right.$, $\left.P_{2}, P_{3}, \ldots P_{n}\right\}$ is the set of risk management actions and $C=\left\{C_{1}, C_{2}, C_{3}, \ldots, C_{m}\right\}$ is the set of risk management objectives. The risk management objectives in $C$ are used to judge the risk management actions in $P$. The aim is to obtain the ranking of risk management actions. Write $a_{i j}$ is the relative weight of risk management action $P_{i}$ against $P_{j}$ for risk management objectives $C_{j}$. The quantified judgements are then recorded in a judgement matrix $A=\left(a_{i j}\right)$.

$A=\left(\begin{array}{lll}a_{11} & a_{12} & \ldots a_{1 n} \\ a_{21} & a_{22} & \ldots a_{2 n} \\ a_{n 1} & a_{n 2} & \ldots a_{n n}\end{array}\right)$

Using the eigenvalue method priority vector obtain for the risk management actions is $\varphi=$ $\left\{\gamma_{1}, \gamma_{2}, \ldots, \gamma_{n}\right\}$ and $\sum_{i-1}^{n} \gamma_{i}=1$.

The importance of the risk management objectives and the actions to achieve the objectives change depending on economic condition. Scenarios representing the economic condition are included in the 
hierarchy. The economy scenarios are categorized as recession, growth and current. Risk management decision is rarely made by one person. To ensure each member's opinion in the risk management committee is taken into consideration a level for decision maker is included in the hierarchy. Figure 3 illustrates the hierarchy with the additional levels.

Figure 3: Risk Management Objectives and Actions Extended Hierarchy

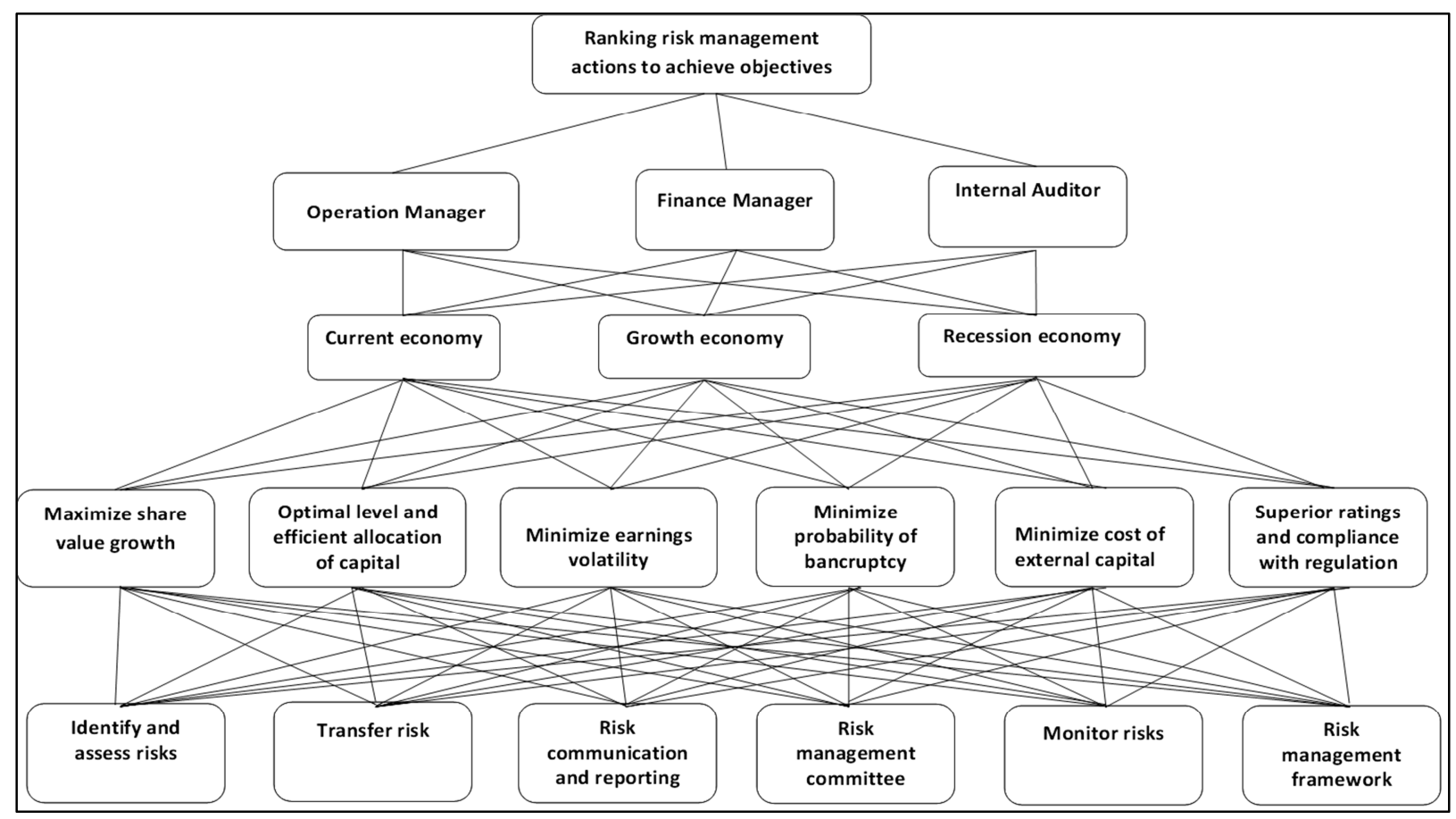

The extended hierarchy has five levels. The first level is the overall goal. The second level is the decision makers. The third level is the economic scenarios. The fourth level is risk management objectives and the fifth level is the risk management actions. The extended hierarchy produces a ranking of the risk management actions perceived by each decision maker based on a different economy scenario.

Write $K=\left\{k_{1}, k_{2}, k_{3}, \ldots, k_{t}\right\}$ is a set of decision makers. $A^{k}=\left(a_{i j}^{k}\right)$ is the judgement matrix from the $k$ decision maker. $\varphi^{k}=\left\{\gamma_{1}, \gamma_{2}, \ldots, \gamma_{n}\right\}$ is the priority vector of decision maker $k$. Each decision maker will have a unique priority vector. AHP supports aggregation of individual judgement. However, in risk management problem comparing the priorities promote further discussions on the problem. Getting the priorities is part of solving the problem. The other part is to elicit information from the decision makers to improve understanding of the problem. The benefits of AHP are beyond just producing ranking for risk management actions. The following discusses benefits of AHP to risk management decision problem.

Elicit and organize information. Using AHP to structure a problem opens up the discussion on the fact and factors influencing the problem. In the risk management example, structuring the problem forces discussions on the competing priorities of the risk management actions and the linkage to the risk management objectives. Decisions in risk management are rarely made by one person. A different decision makers have different perception of a problem. AHP also facilitates decision makers to reach agreement on critical factors influencing the solutions of the problem.

Create a transparent problem. Organizing information in a hierarchy makes the problem more transparent to the risk management committee and other department managers. The hierarchy precisely shows the alternatives and the criteria to evaluate the alternatives. The hierarchy also shows trade-off decision maker has to make in choosing one criteria over another.

Capturing inconsistency between decision makers. The consistency index captured inconsistency in the pairwise comparison judgement of a decision maker. However, AHP can capture inconsistency beyond the computation of individual decisions. In the risk management problem the priority vectors obtain from each decision maker are compared. A significant difference in the ranking raises questions about the reasons behind the differences. Interview or discussion is required to elicit information from 
the decision maker to clarify the differences. If necessary the problems need to be reviewed and amend. For risk management problem AHP is not just a tool to obtain the priorities but AHP is a process of learning, understanding and improving a problem.

\section{Conclusion}

This paper discusses possible applications of AHP to risk management decision making. The complexity of risk management problems requires a decision making tool able to incorporate both risk management principles and multiple conflicting factors influencing the problem. The risk management objectives and actions example shows how AHP can structure a risk management decision making problem. The aim is to prioritize risk management actions to achieve risk management objectives. Risk management is a tool to elicit and make explicit a risk manager's understanding of the effect of risk to business objectives. Risk management assists managers in assessing risks, planning and implementing detailed responses to risks. AHP is a decision making tool to improve risk manager's decision making in risk management. AHP assists risk managers in structuring and simplifying complex problems for objective decision making.

\section{REFERENCES}

Acharyya, M. (2009). The influence of enterprise risk management on insurer stock market performance: An event analysis. 2009 Enterprise Risk Management Symposium.

Barton, T., Shenkir, W., \& Walker, P. (2002). Making enterprise risk management pay off: How leading companies implement risk management. Financial Times Prentice Hall.

Beasley, M., Pagach, D., \& Warr, R. (2008). Information conveyed in hiring announcements of senior executives overseeing enterprise-wide risk management processes. Journal of Accounting, Auditing and Finance, 23 (3), 311-332.

Borge, D. (2001). The book of risk. John Wiley \& Sons Inc.

Cox Jr, A., et al. (2008). What's wrong with risk matrices? Risk Analysis, 28 (2), 497-512.

Eshlagy, A. T., \& Homayanfar, M. (2011). Multi criteria decision making methodologies and applications: A literature review from 1999 to 2009. Research Journal of International Studies, 21 , 86137.

Forman, E., \& Gass, S. (2001). The analytic hierarchy process: An exposition. Operations research, 469-486.

Gordon, L., Loeb, M., \& Tseng, C. (2009). Enterprise risk management and firm performance: A contingency perspective. Journal of Accounting and Public Policy, 28 (4), 301-327.

Grunig, R., \& Kuhn, R. (2005). Successful decision making: A systematic approach to complex problems. Springer -Verlag.

Hopkin, P. (2010). Fundamentals of risk management: Understanding, evaluating and implementing effective risk management. The Institute of Risk Management.

Hoyt, R. E., \& Liebenberg, A. P. (2011). The value of enterprise risk management. Journal of Risk and Insurance, 78 (4), 795-822.

Iyer, S. R., Rogers, D. A., \& J. Simkins, B. (2010). Academic research on enterprise risk management. In J. Fraser \& B. J. Simkins (Eds.), Enterprise risk management: Today's leading research and best practices for tomorrow executives (p. 419-43-). New Jersey: John Wiley \& Sons.

Nocco, B., \& Stulz, R. (2006). Enterprise risk management: Theory and practice. Journal of Applied Corporate Finance, 18 (4), 8-20. 
Pagach, D., \& Warr, R. (2011). The characteristics of firms that hire chief risk officers. The Journal of Risk and Insurance, 78 (1), 185-211.

Panning, W. H. (2006, April 2006). Managing the invisible: Measuring risk, managing capital and maximizing value. 2006 Enterprise risk management symposium.

Ping Zhuang, H. H., Yanxi XI, \& Qu, T. (2008). Visualization of current core research groups of enterprise risk management. In Fifth international conference on fuzzy systems and knowledge discovery.

Saaty, T. L. (1980). The analytic hierarchy process. McGraw - Hill.

Saaty, T. L. (1990). How to make a decision: The analytic hierarchy process. European Journal of Operational Research (48), 9-26.

Sipahi, S., \& Timor, M. (2010). The analytic hierarchy process and analytic network process: An overview of applications. Management Decision, 48 (5), 775-808.

Stuer, R. E., \& Na, P. (2003). Multiple criteria decision making combined with finance: A categorized bibliographic study. European Journal of Operational Research (150), 496-515.

Toneguzzo, J. P. (2010). How to allocate resources based on risk. In J. Fraser \& B. J. Simkins (Eds.), Enterprise risk management: Today's leading research for tomorrow's executives (p. 189-216). John Wiley and Sons.

Vaidya, O. S., \& Kumar, S. (2006). Analytic hierarchy process: An overview of applications. European Journal of Operational Research (169), 1-29.

Verbano, C., \& Venturini, K. (2011). Development paths of risk management: Approaches, methods and fields of application. Journal of Risk Research, 14 (5), 519-550.

Zopounidis, C., \& Doumpos, M. (2002). Multi-criteria decision aid in financial decision making: Methodologies and literature review. Journal of Multi-Criteria Decision Analysis, 11 (4-5), 167-186. 